\title{
Heightening of very high gravity dams: the case study of the Grande Dixence
}

\author{
Basile Clerc, Dr. Giovanni De Cesare, Dr. Pedro Manso \\ E-Mail: basile.clerc17@gmail.com; giovanni.decesare@epfl.ch; pedro.manso@epfl.ch
}

\section{Motivation}

Dam heightening can provide large incremental positive impacts on storage with minimum incremental negative impacts, but requires deep knowledge of the structure and its foundation. Very high gravity dams are usually well studied and documented due to their importance and complexity. Such profound knowledge of the dam-reservoir-foundation system considerably reduces the uncertainty about site conditions already at an early stage of design. Furthermore, the availability of monitoring data and safety assessment tools (FE models, predictive behaviour models) strongly reduce the preparation time to reach feasible design solutions.

The Grande Dixence dam, located in the Canton of Valais, creates the largest reservoir in Switzerland, providing $10 \%$ of the country's storage energy. If heighten this dam could be used to transfer a larger share of the summer inflows to produce electricity in winter.

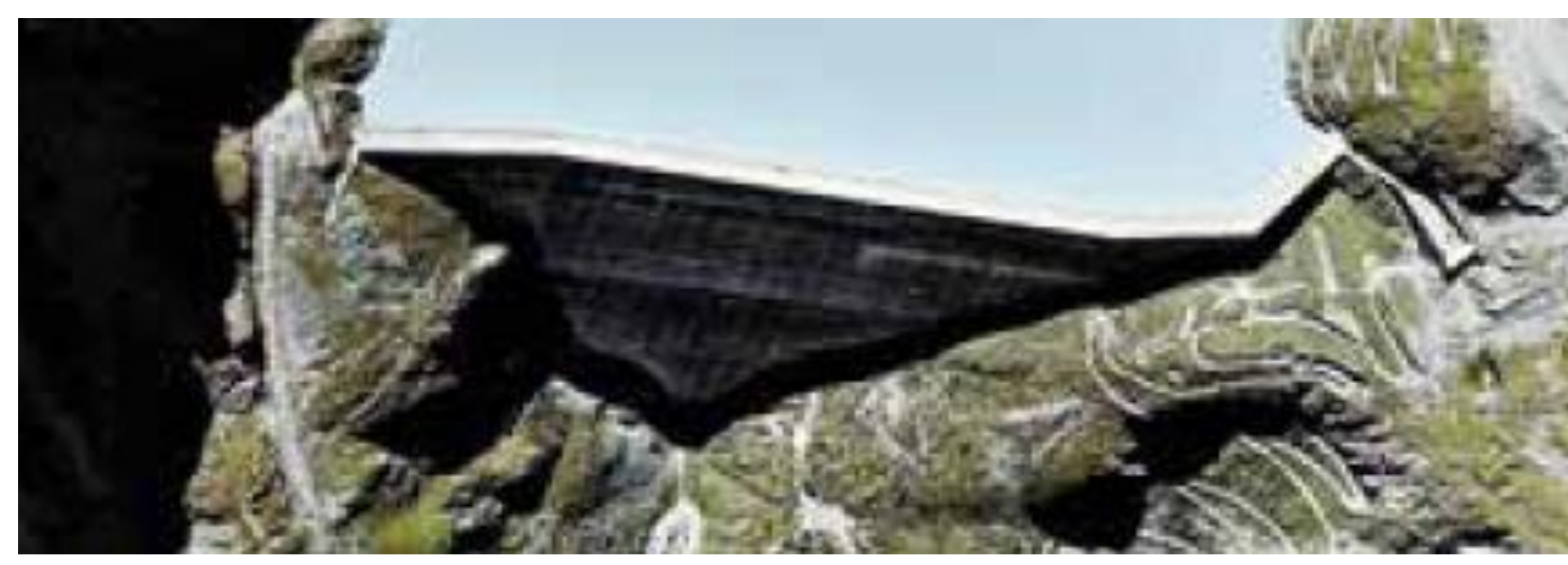

Top view of the Grande Dixence dam

\section{Methods}

The methodology consists of two main steps. The first step evaluates the reference state of the studied hydroelectric scheme to identify major constraints, while the second step consists of analysing and generating heightening solutions. The analysis of the results obtained during both prior stages should allow an assessment of the developed variants to determine the optimal solution.
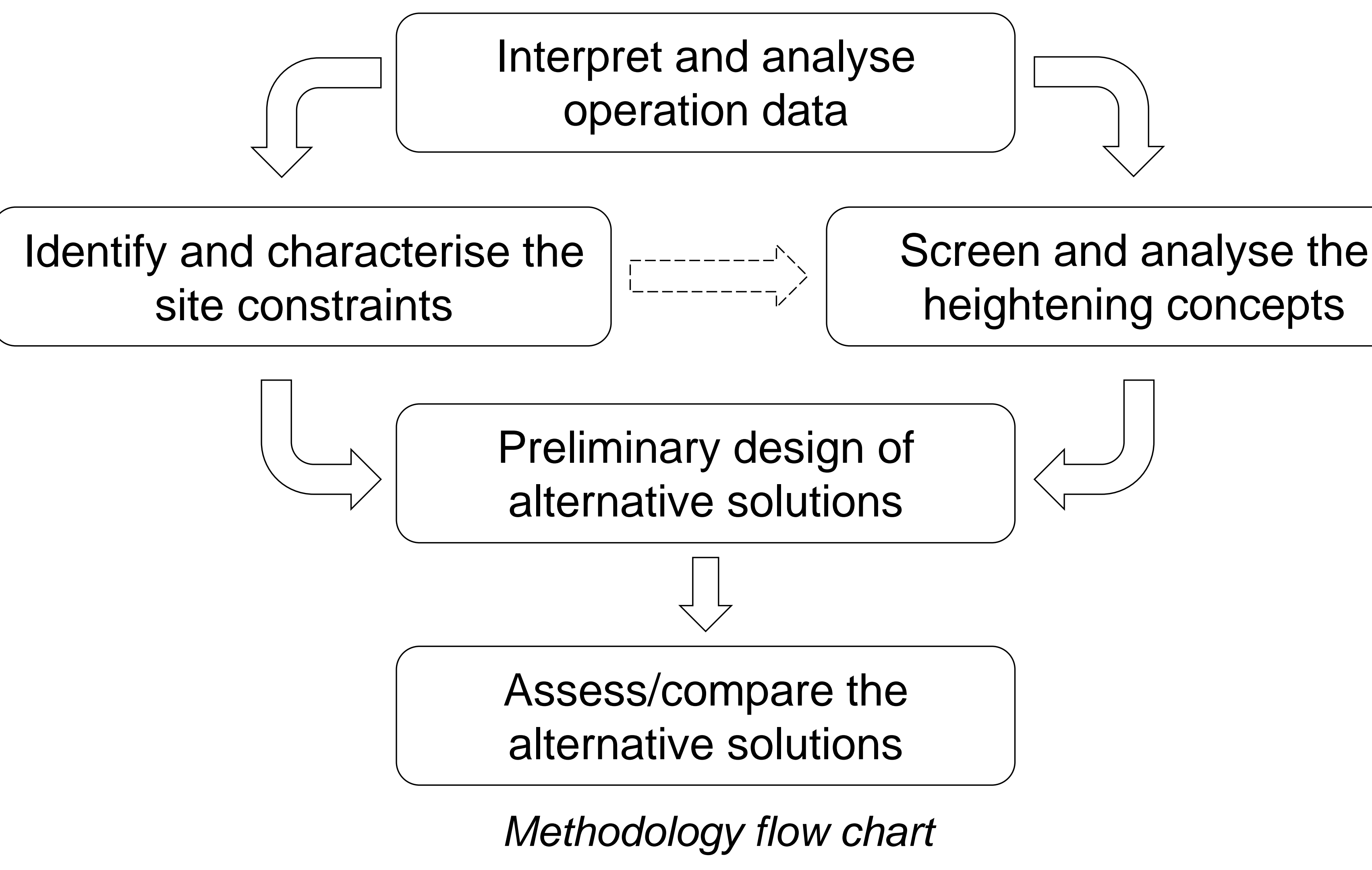

Results

Submersion of the collector Heightening

Pressure increase

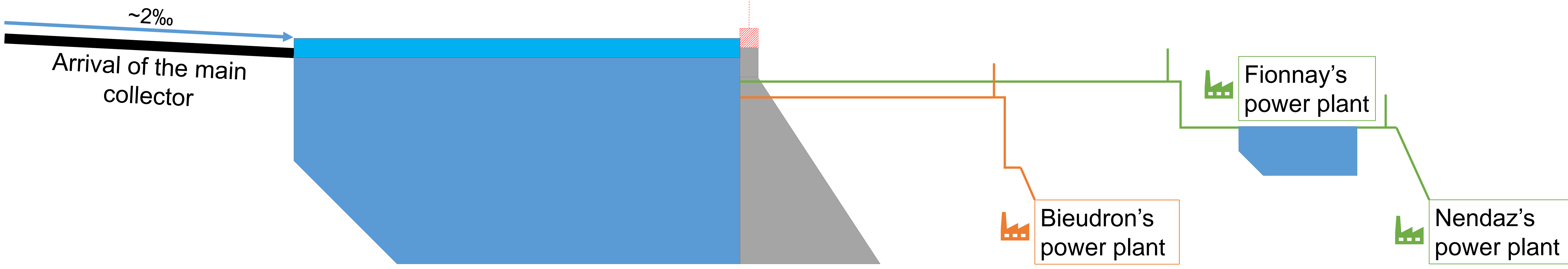

Grande Dixence simplified scheme (not to scale)

\section{Screening of heightening concepts}

Several heightening solutions were considered, but constraints were quickly acknowledged [1]. The plan shape of the dam crest strongly limits the integration of an arch and the presence of joints every $16 \mathrm{~m}$ is a strong constraint to any solution of buttress or multiple-arch heightening concepts.

Considering building artificial abutments and/or using post-stressed anchors was also investigated. However, the use of $300 \mathrm{~m}$ long anchors is technically unheard off and challenging and has been discarded.

In summary, due to its easier implementation and higher flexibility in regards to the geometry of the actual dam, a similar structural concept was preferred from inception when considering joint behaviour of the original and heightened structures.

This concept lead to retaining four alternative solutions for comparison, all with a new crest width of $5 \mathrm{~m}$. Investigations cover height increase solutions from few meters up to maximum $30 \mathrm{~m}(\sim 10 \%$ of the existing dam height). Key differences are the water column over the upstream face of the height increase and the location of its gravity centre with regards to the main structure.

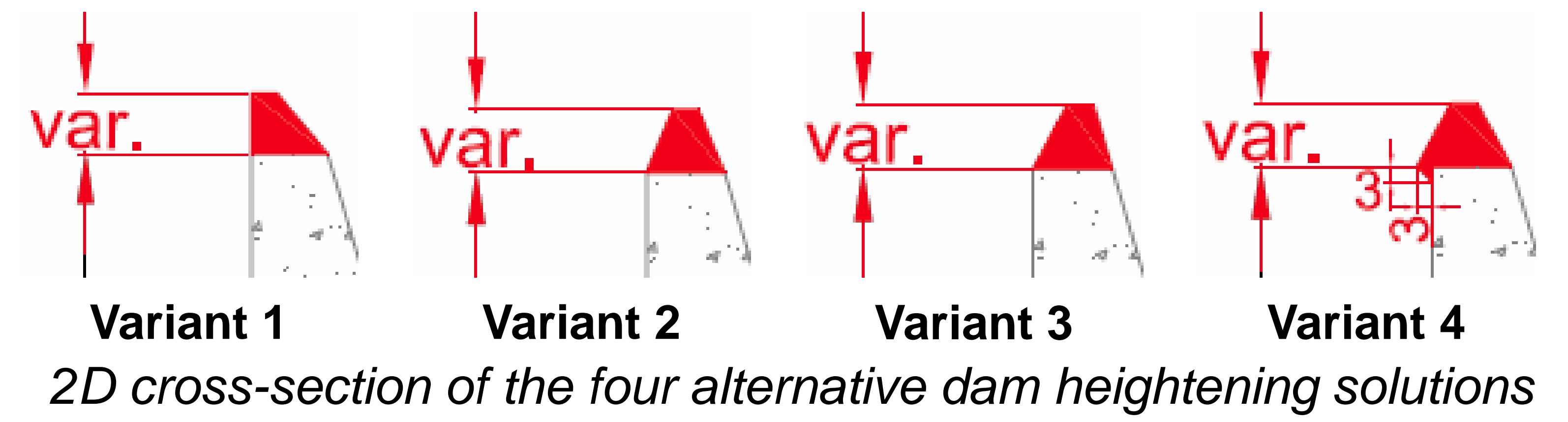

\section{Verification results analysis}

The verification analysis shows satisfactory results as all variants meet the design criteria.

\section{Major constraints}

As seen on the simplified diagram above, the height increase solutions would submerge the main conveyance tunnel outlet and the backwater effects modify pumping and aeration conditions farther upstream. Moreover, the water pressure increases on the waterways leading to both powerplants downstream: although Bieudron's surge tank can withstand the increase, Fionnay's cannot without adaptation measures.

\section{Economic analysis}

A preliminary analysis of the Levelized Cost of Electricity (LCOE) indicates a remarkably low cost price and point out that a height increase within 10 to $15 \mathrm{~m}$ would likely be optimal.

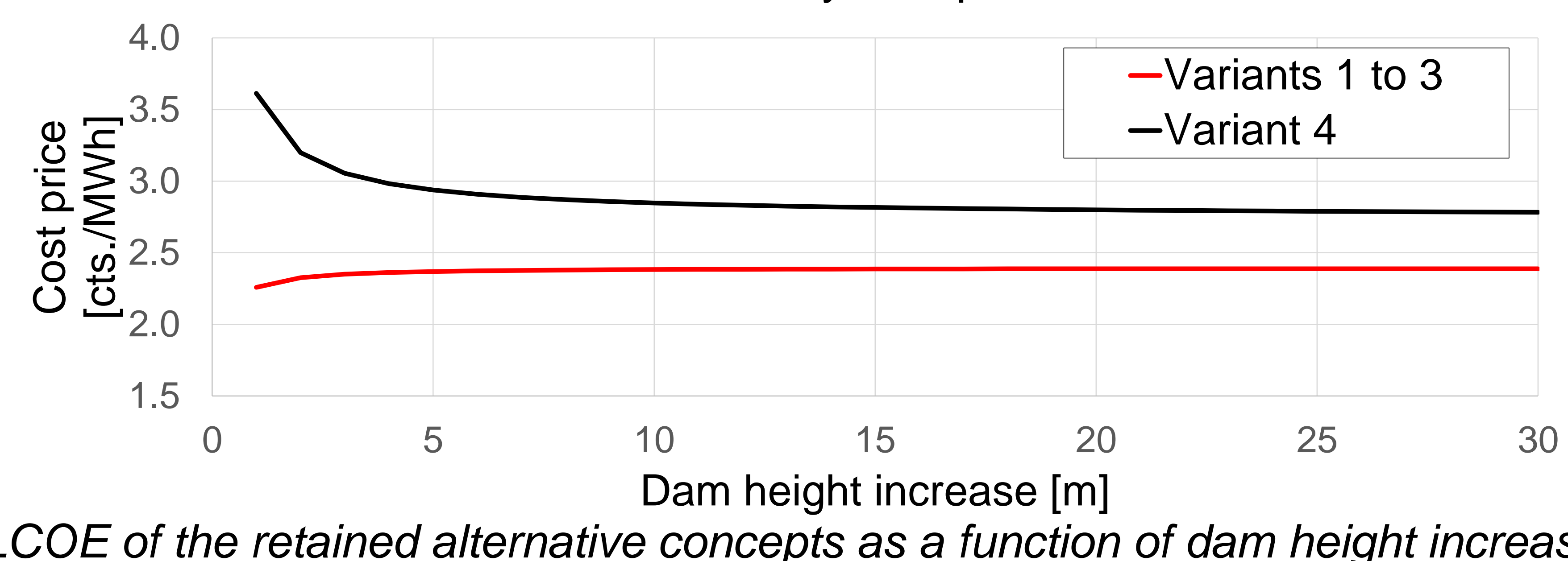

\section{References}

[1] Clerc, B., Manso, P., De Cesare, G. (2019) Heightening of very high gravity dams: the case study of the Grande Dixence. International Benchmark Workshop on Numerical Analysis in Dams, Open Theme, Milan (in press).

[2] Office fédéral de l'énergie OFEN. (2015). Directive sur la sécurité des ouvrages d'accumulation, Parties A à E.

[3] Schleiss, A. J., Pougatsch, H. (2011). Traité de Génie Civil volume 17 : Les barrages. Presses polytechniques et universitaires romandes, Lausanne.

[4] Schaefli, B., Manso, P., Fisher, M., Huss, M., \& Farinotti, D. (2019). The role of glacier retreat for Swiss hydropower production. Renewable Energy, Volume 132. 